Int. J. Morphol.,

30(3):1150-1157, 2012.

\title{
Morphologic Alterations Resulting from Denervation of the Diaphragm in Rats
}

\author{
Alteraciones Morfológicas Resultantes de la Denervación del Diafragma en Ratas
}

${ }^{*}$ M. M. Torrejais; ${ }^{* * *}$ J. C. Soares; ${ }^{* *}$ S. M. M. Matheus; ${ }^{* *}$ L. A. D. Francia-Farje; ${ }^{* * * *} J$. M. Mello \& ${ }^{* * * *}$ E. J. D. Vicente

TORREJAIS, M. M.; SOARES, J. C.; MATHEUS, S. M. M.; FRANCIA-FARJE, L. A. D.; MELLO, J. M. \& VICENTE, E. J. D. Morphologic alterations resulting from denervation of the diaphragm in rats. Int. J. Morphol., 30(3):1150-1157, 2012.

SUMMARY: The morphological alterations that occur in the muscle fibers of denervated rat diaphragms were studied. Fifteen adult male albino rats (Rattus norvegicus) with a mean weight of $200 \mathrm{~g}$ and about 60 days of age were used. Chronically denervated diaphragms were obtained and the animals were sacrificed after 4, 8 and 12 weeks of denervation. The left antimere of the diaphragm was denervated by sectioning of the phrenic nerve and the right antimere served as control. Each antimere was divided into two fragments, which were used for histological (H.E.) and histoenzymological (NADH-TR and myofibrillar ATPase). After 4 weeks, denervated muscle fibers showed important light microscopic alterations: atrophy with angular profiles in cross-sections, cytoplasm containing vacuoles, enlarged interstitial space with increased connective tissue, cellular infiltration, and muscle fibers without defined contours. The most marked alterations being observed for type IIb and IIa fibers. Eight and 12 weeks after denervation, the NADH-TR reaction showed that it was impossible to characterize the muscle fibers based on their metabolic profile.

KEY WORDS: Diaphragm; Muscle fiber; Denervation; Rat.

\section{INTRODUCTION}

Atrophy is one of the various morphological alterations observed during denervation of striated skeletal muscle, which is characterized by a reduction in muscle fiber size. Different patterns of atrophy can be identified during the process of motor denervation. If denervation is complete, all muscle fibers undergo atrophy. In contrast, in the case of partial motor denervation, isolated or groups of atrophic fibers are observed among groups of normal fibers (Cullen et al., 1992). Atrophic fibers, when observed in cross-sections, frequently lose their polygonal shape, forming angulations in the sarcolemma, and show intense oxidative activity, being intensively stained by nonspecific esterase. These fibers represent the so-called "dark angular atrophic fibers" (Harriman, 1990; Cullen et al.).

In addition to the alterations described, a variable proportion of muscle fibers enter an irreversible process of degeneration after long periods without innervation (McComas, 1977; Anzil \& Wernig, 1989). The affected muscle cells become swollen and, together with their nuclei, start to fragment. Vacuoles appear in the cytoplasm, basophilia increases, and the striations become less distinct before the fibers disintegrate. Phagocytic cells accumulate at the sites of necrosis which participate in the process of removal of muscle fiber remnants. Complete destruction of a muscle fiber may finally occur (McComas), but there is no doubt that some muscle fibers conserve their characteristic striations even when denervation continues for a long period of time (Anzil \& Wernig).

The first histochemical observations made on striated skeletal muscles of rats and mice indicated significant differences in the behavior of distinct fiber types during the process of denervation. According to Karpati \& Engel (1968), the atrophic process may indiscriminately involve both type I and type II fibers. Histochemical analysis has shown that type II fibers are generally atrophied first during the process of denervation, whereas type I fibers generally show a variable behavior in different muscles depending on their physiological characteristics.

\footnotetext{
* Medical and Pharmaceutic Sciences Center, UNIOESTE, Cascavel, Paraná, Brazil.

** Department of Anatomy, IB, UNESP, Botucatu, São Paulo, Brazil.

*** Department of Morphology Sciences, UEM, Maringá, Paraná, Brazil.

***** Department of Physiotherapy, UFJF, Juiz de Fora, Minas Gerais, Brazil.
} 
Particularly with respect to human skeletal muscles, determination of the effects of muscle fiber denervation becomes difficult because in most neurogenic disorders denervatedand reinnervated fibers are present side by side in samples removed for diagnosis. Highly atrophic fibers might safely be considered denervated, whereas less atrophic fibers may represent both fibers in the process of atrophy and those in the process of reinnervation and recovery. On the other hand, atrophy due to denervation can be sequentially analyzed in completely denervated muscles of animals (Engel \& Banker, 1994).

Representing a striated skeletal muscle with special functional characteristics considering its uninterrupted activity throughout the life of a healthy individual, the diaphragm is an attractive model for the study of events associated with the process of denervation. Another relevant aspect is that the normal hemidiaphragm, in addition to satisfactorily maintaining the respiratory conditions of the animals, serves as a control for morphological or functional evaluation.

\section{MATERIAL AND METHOD}

All experimental procedures were conducted in accordance with the Ethical Principles of Animal Experimentation adopted by the Brazilian College of Animal Experimentation (COBEA) and the study was approved by the Ethic Committee on Animal Experimentation (CEEA IB-UNESP) on June 2, 1999.

Fifteen adult male albino rats (Rattus norvegicus) with a mean weight of $200 \mathrm{~g}$ and about 60 days of age, obtained from the Central Animal House, UNESP, Botucatu Campus, SP, Brazil, were used. The animals were anesthetized with intraperitoneal injections of $3 \%$ sodium pentobarbital $(1.0 \mathrm{mg} /$ $\mathrm{kg}$ ). Preparations of chronically denervated diaphragm were obtained according to the method of Brazil (1965) described for rats.

Five animals from each group were sacrificed 4,8 and 12 weeks after denervation. The left antimere of the diaphragm was used as the experimental specimen and the right antimere served as control. Each hemidiaphragm was divided into two fragments, which were used for muscle fiber analysis by light microscopy.

Anatomical Observations. For anatomical analysis of the denervated diaphragms, specimens were removed en bloc, i.e., the muscle connected to the caudal wall of the chest which comprises a segment of the vertebral spine, part of the sternum and more caudal ribs.
Histological and Histoenzymological Study of Muscle Fibers. For analysis of the muscle fibers, the diaphragm was removed and kept at room temperature for 30 to 40 min (Khan, 1977). The material was then covered with talc for tissue preservation (Moline \& Glenner, 1964) and frozen in liquid nitrogen for $2 \mathrm{~min}$. The muscle segments were transferred to a Leica CM 1800 Cryostat chamber (cidade, Germany) at $-20 \mathrm{oC}$ and incubated for 1 hour (Pullen, 1977). Next, one end of these segments was glued to a metal support with Tissue Freezing Medium (LeicaJung, Germany), and 7- $\mu \mathrm{m}$ thick cross-sections of the muscles were obtained.

The sections were submitted to routine staining with hematoxylin-eosin (HE) for morphological analysis and to the following reactions: nicotinamide adenine dinucleotide- tetrazolium reductase (NADH-TR) (Pearse, 1972) modified by Dubowitz \& Brooke (1973) for the analysis of oxidative and glycolytic metabolism, and myofibrillar ATPase (mATPase) at pH 9.4 after preincubation in acid $(\mathrm{pH}$ 4.6) and alkaline $(\mathrm{pH} 10.2)$ medium (Dubowitz \& Brooke, 1973) for the analysis of contractile characteristics. A Zeiss Axiophot II photomicroscope was used for microscopic observation and photodocumentation.

\section{RESULTS}

Anatomical observations. Two and 4 weeks after muscle denervation, the left hemidiaphragm was found to be transparent and the muscle fibers were less dense but still visible. In animals sacrificed after 8 and 12 weeks (Fig. 1 ), the same diaphragmatic portion was completely translucent, with no muscle fibers being noted close to the tendinous center. However, muscle fibers were observed close to the ribs, a finding characterizing peripheral innervation of the diaphragm originating from intercostal nerves.

Observation of these specimens by transillumination permitted a perfect control of the efficacy of the denervation procedures performed at the beginning of the study.

Histological and histoenzymological study of muscle fibers. Analysis of the muscle fibers present in the rat diaphragm after different times of treatment was done using cross-sections stained with H.E. and reacted for NADHTR and mATPase after preincubation at pH 4.6 and 10.2. The muscle fibers were classified as proposed by Brooke \& Kaiser (1970). 


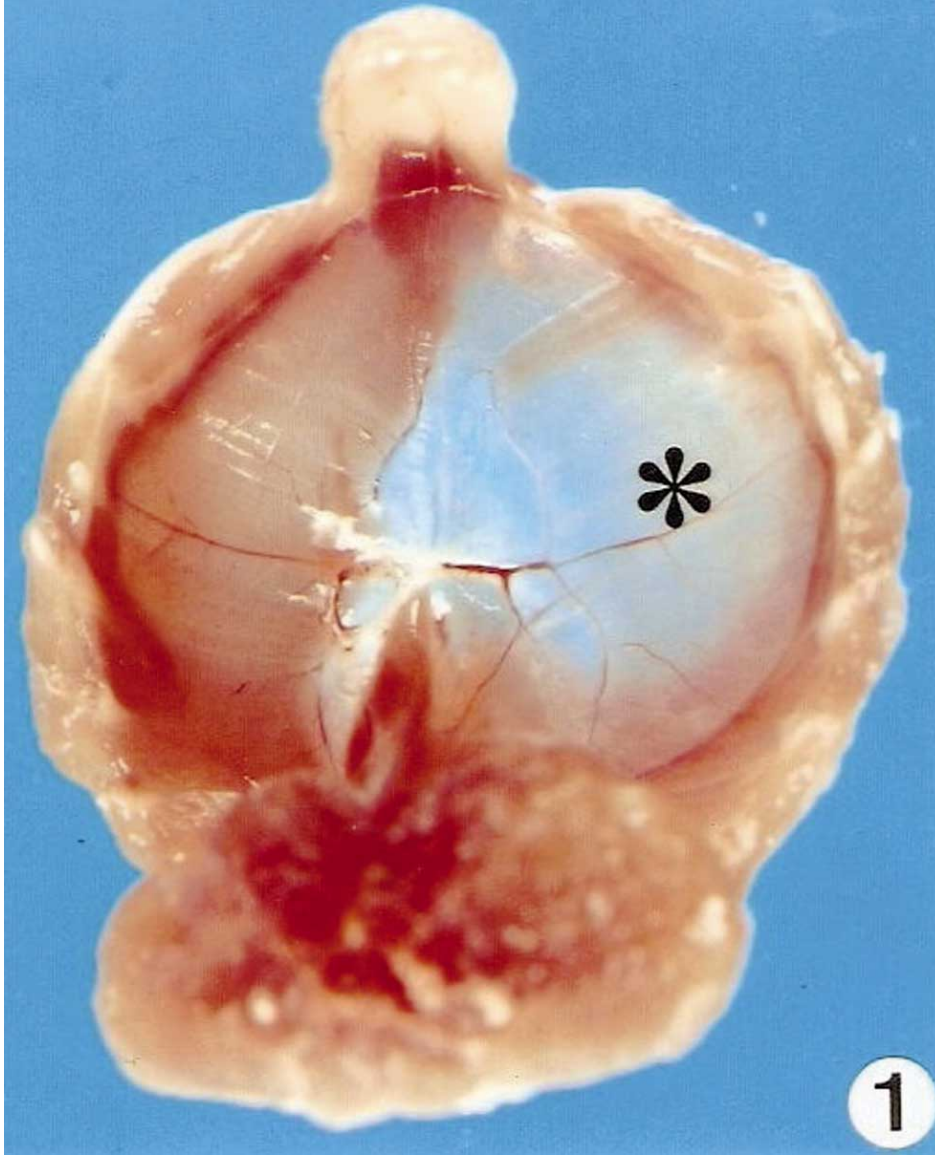

Fig. 1. Caudal view of the rat diaphragm isolated 12 weeks after denervation. Right antimere - control; left antimere - denervated (*).

Control group. Analysis of HE-stained skeletal muscle fibers of the rat diaphragm showed preserved general architecture, i.e., the fibers were organized into bundles surrounded by normal connective tissue (perimysium) and each fiber of a polygonal or round shape and with peripheral nuclei was covered with connective tissue (endomysium) (Fig. 2A).

The NADH-TR reaction revealed the presence of fibers with a small diameter (intense oxidative activity) corresponding to type I fibers, fibers with intermediate diameter (moderate oxidative activity) corresponding to type IIa, and large diameter fibers (weak oxidative activity) corresponding to type IIb (Fig. 2B). The mATPase reaction after preincubation at $\mathrm{pH} 4.6$ demonstrated the presence of type I (small diameter - strong reaction) and type II fibers (intermediate or large diameter - weak reaction) (Fig. 2C). An opposite behavior was observed for muscle fibers submitted to the mATPase reaction after preincubation at $\mathrm{pH} 10.2$ (Fig. 2D). These reactions demonstrated a random distribution of different fiber types in the rat diaphragm, characterizing a mosaic pattern.

Denervated group after 4 weeks. In the animals of this group, the striated skeletal muscle fibers showed the following alterations: atrophy and angular contour, enlarged interstitial space containing increased amount of connective tissue, heterogenous intracellular staining, and cytoplasm containing small vacuoles (Fig. 3A).

Histoenzymological analysis of the diaphragm showed muscle fibers without defined contours, with the most marked alterations in terms of size and metabolic profile being observed for type IIb and IIa fibers. In contrast, type I fibers seemed to be more preserved (Fig. 3B). The mATPase reaction after preincubation at acid $\mathrm{pH}$ better characterized the types of muscle fibers: type II fibers showed vacuolized cytoplasm while the aspect of type I fibers was closer to normal. In contrast, after preincubation at alkaline $\mathrm{pH}$ mATPase-stained muscle fibers appeared diffuse and the cytoplasm contained large vacuoles, with the differentiation between muscle fiber types not being possible (Fig. 3C and 3D).

Denervated group after 8 weeks. Histological analysis of HE-stained muscle fibers demonstrated profound morphological alterations. These changes were characterized by small caliber fibers and angular profiles among large caliber fibers that contained large intracytoplasmic vacuoles which conferred them an apparent caliber increase, in addition to bizarre shapes. The staining distribution through the cytoplasm was not homogenous. In the interstitial space, increase in connective tissue was observed compared to the control group, mainly in the perimysial region, depriving the muscles of their classical structure (Fig. 4A). The NADH-TR reaction demonstrated that it was virtually impossible to identify muscle fibers based on their metabolic profile (Fig. 4C).

Denervated group after 12 weeks. The finding that calls attention in cross-sections 12 weeks after denervation is the marked reduction in diaphragm thickness (Figs. 4B and 4D). Muscle fiber atrophy was clearly visible, intracytoplasmic vacuoles were present in practically all muscle fibers, and a marked increase in intercellular connective tissue was evident. Most cellular profiles showed angular contours and the nuclei appeared to be dense and small (Fig. 4B). The NADH-TR reaction showed that it was impossible to recognize distinct cellular elements in the diaphragm (Fig. 4D). 

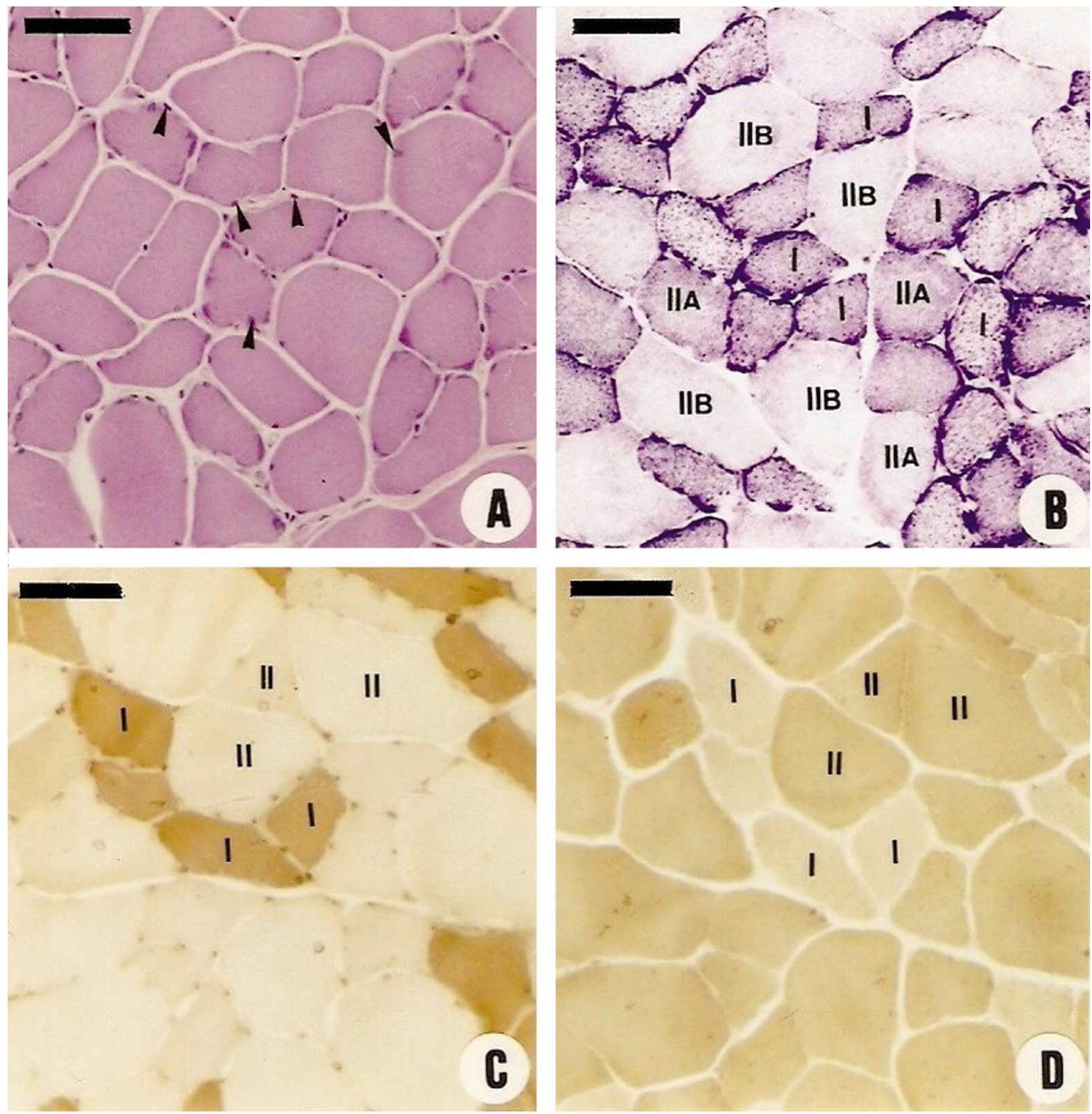

Fig. 2. Photomicrographs of cross-sections of the rat diaphragm. Bar $=25 \mu \mathrm{m}$. A: Normal general architecture; peripheral nuclei (arrowheads). Control group, 4 weeks. HE. B: Small diameter fibers (I), intermediate diameter fibers (IIA), and large diameter fibers (IIB). Control group, 4 weeks. NADH-TR, 400X. C: mATPase reaction, $\mathrm{pH}$ 4.6: type I fibers - strong reaction; type II fibers - weak reaction. Control group, 12 weeks. D: mATPase reaction, pH 10.2: type I fibers - weak reaction; type II fibers - strong reaction. Control group, 12 weeks.

\section{DISCUSSION}

Denervation of the diaphragm was successful as demonstrated by macroscopic observations of specimens removed en bloc and examined by transillumination. The procedure proposed by Brasil was found to be simple and fast and showed a high success rate indicated by low morbidity considering the extent and location of the surgical lesions. 

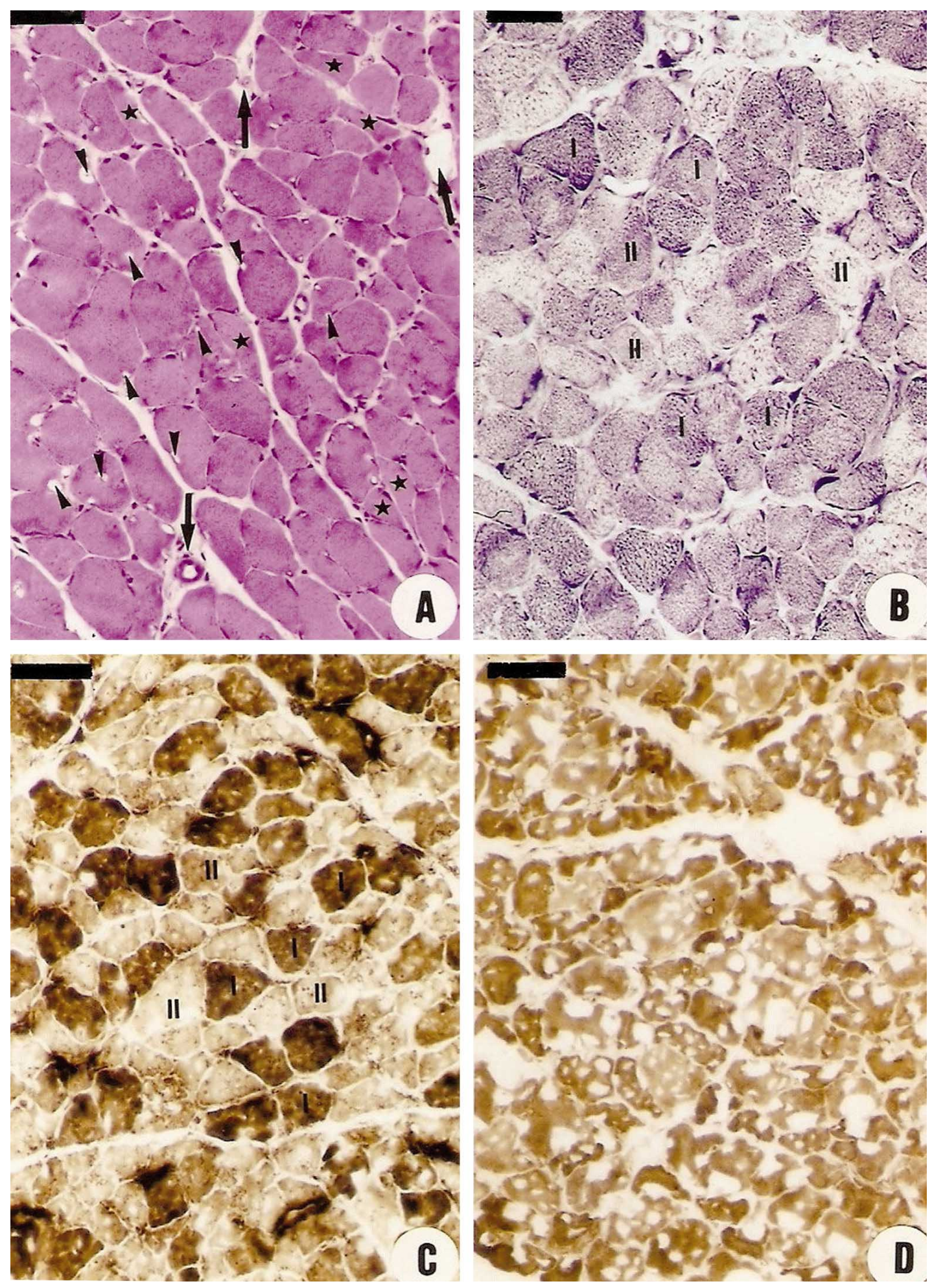

Fig. 3. Photomicrographs of cross-sections of the rat diaphragm 4 weeks after denervation. Bar $=25 \mu \mathrm{m}$. A: Atrophic fibers with angular contours $(*)$. Interstitial space containing a larger amount of connective tissue (arrows) and cytoplasm with small vacuoles (arrowheads). HE. B: Note that type II fibers are less preserved than type I fibers. NADH-TR. C: mATPase reaction, $\mathrm{pH}$ 4.6: type II fibers show a vacuolized cytoplasm while the aspect of type I fibers is closer to normal. D: mATPase, $\mathrm{pH}$ 10.2: large vacuoles are observed in the cytoplasm, and no differentiation between muscle fiber types is possible. 

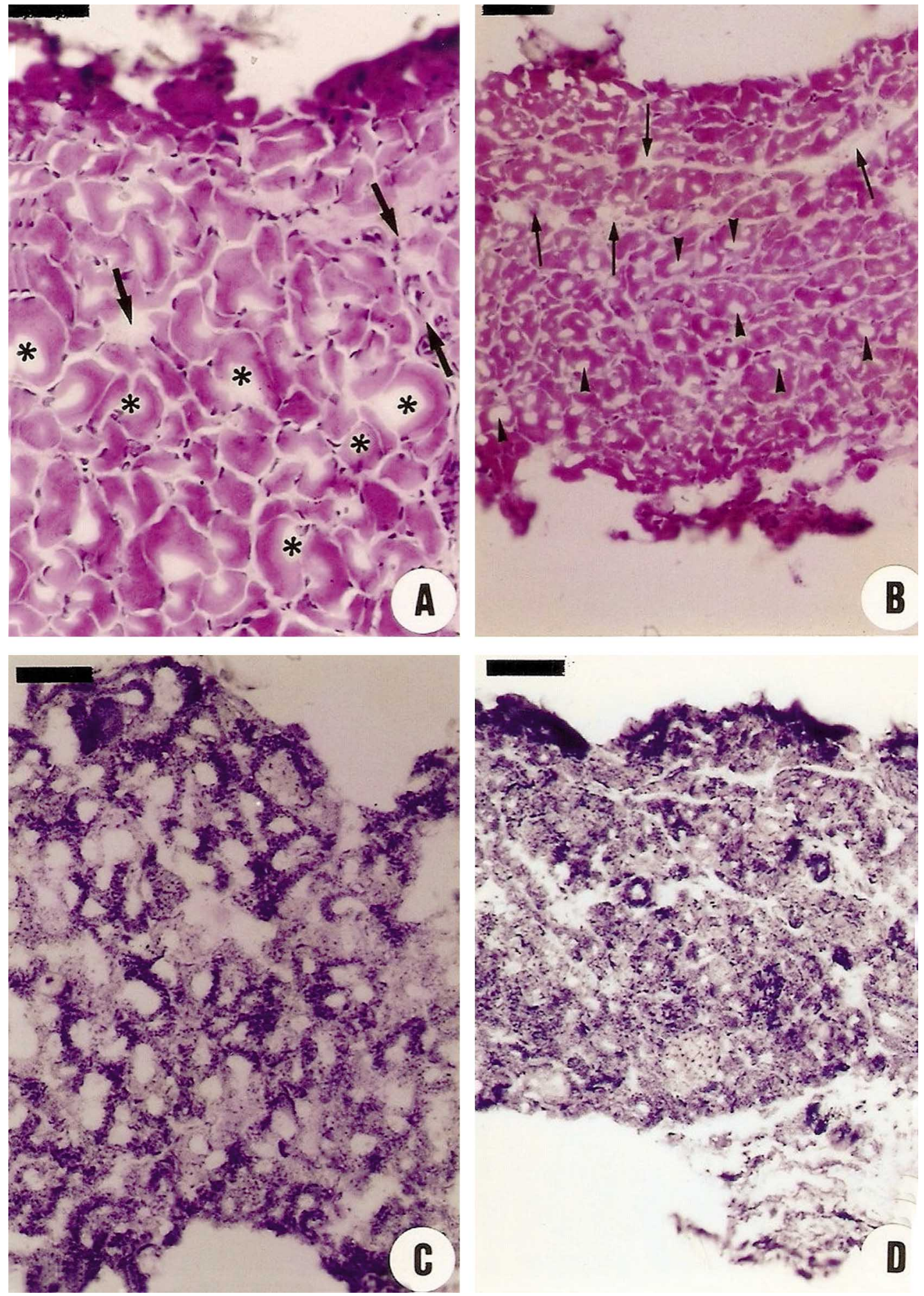

Fig. 4. Photomicrographs of cross-sections of the denervated rat diaphragm. Bar $=25 \mu \mathrm{m}$. A: Large intracytoplasmic vacuoles (*); interstitial space infiltrated with connective tissue (arrows). Denervated group after 8 weeks. HE. B: All muscle fibers are atrophied. Note the connective tissue in the interstitial space (arrows) and the intracytoplasmic vacuoles (arrowheads). Denervated group after 12 weeks. HE. C and D: NADH-TR reaction: muscle fibers cannot be characterized based on their metabolism. Denervated groups after 8 and 12 weeks, respectively. 
Histological analysis of the rat diaphragms demonstrated the typical structural organization of other mammalian striated skeletal muscles. Histoenzymological techniques showed that two main types of fibers, called type I and type II, predominate in the rat diaphragm: small caliber fibers showing intense oxidative metabolic activity and high reactivity to mATPase at acid $\mathrm{pH}$, and large caliber fibers showing low oxidative activity and higher reactivity to mATPase at alkaline $\mathrm{pH}$. Distribution of the fibers in the muscle follows a mosaic pattern, i.e., they are randomly intermingled and do not form clusters. According to Edström \& Kugelberg (1968), this arrangement prevails in most striated skeletal muscles, with a percent predominance of one or the other fiber type in different muscles or even in certain regions of the same muscle. Fibers with similar functional characteristics are part of the same motor unit.

In animals submitted to neurotomy, histological analysis demonstrated that the degree of atrophy and vacuolization progresses with time. The vacuolized areas apparently deprived of contractile elements and mitochondria observed in the present study in cross-sections of denervated fibers have been called "multicores" by most investigators and correspond to small and numerous areas where oxidative enzyme activity is minimal. These structures were mainly observed in type II fibers at the initial stages of diaphragm denervation. However, according to the literature, "multicore" areas are normally found in both type I and type II fibers (Engel et al., 1971). According to these authors, in cross-sections most lesions do not exceed $20 \mu \mathrm{m}$ in diameter, and mitochondria and myofibrils are depleted in these areas.

Normally, vacuoles are detected in different stages of denervation, as well as in other myopathies. Vacuoles observed during denervation represent a common alteration and originate in a series of muscle disorders, with none of the types described constituting a basis for the diagnosis of a given pathology or being particularly associated with a specific disorder (Engel, 1973). In the specific case of denervation, vacuoles are filled with multilaminate membranous structures accompanied by glycogen granules, dense bodies and fibrillar or amorphous material. Although some vacuolar characteristics can be inferred from specific staining and light microscopy observations, ultrastructural analysis is the method of choice for the definitive characterization of the type of deposit present in vacuoles as emphasized by Scriver et al. (1989).

In the present study, muscle fiber atrophy progressed up to 12 weeks, also reflecting on diaphragm thickness. Many of these fibers are found to be highly reactive to oxidative enzymes. The basic mATPase also shows intense activity (Banker \& Engel, 1994). Atrophic fibers with a highly angular profile became frequent after 8 weeks of denervation. Earlier observations demonstrated that type I fibers better resisted the early phases of denervation maintaining, at least in part, their morphological and metabolic characteristics.
During later evaluations, the marked presence of vacuoles and the indistinct contours of the muscle fibers impaired their morphological and metabolic characterization. These reactivity properties, although typical of the denervation process, differ from those of angular fibers observed in other pathological neurogenic processes such as polymyositis and myotonic dystropy (Banker \& Engel).

After total denervation by sectioning of the motor nerve, all muscle fibers became atrophied, as observed in crosssections of the rat diaphragm after 12 weeks. In experimental studies on total denervation the size of muscle fibers decreases rapidly. In the study of Engel \& Stonnington (1974), 80\% of fibers of the gastrocnemius and soleus muscles of rats became atrophied within the first weeks after sectioning of the sciatic nerve. After this initial period, the velocity of the atrophy process declined. In the present study, although no quantitative fiber analysis was performed, the microscopic observations after 2 weeks did not reveal drastic lesions in muscle fiber structure. However, 8 weeks after denervation a marked percentage of atrophic fibers was observed. This difference in the occurrence of muscle atrophy between that study and the present one seems to be related to the functional characteristics of the muscles studied in each case.

A considerable increase of connective tissue in the interstitial spaces was observed by week 8 of denervation and became marked after 12 weeks. According to Cotran et al. (1999), the presence of connective tissue is discrete during the initial phase of denervation which is characterized by few fibers and lymphocyte infiltrates in the interstitial spaces. With total degeneration of the muscle fibers, this original space of each fiber is filled with connective tissue consisting of collagen fiber bundles, fibroblasts and a lymphocytic infiltrate. Banker $\&$ Engel emphasized that the more severely affected the muscle, the more conspicuous will be the proliferation of connective tissue. Particularly during denervation, initially there is proliferation of perimysial tissue, with an increase in endomysial tissue only occurring after marked fiber loss in the muscle bundles, as demonstrated in the present study after 8 and 12 weeks.

Analysis of the present results and comparison with data reported in the literature permit us to conclude that after denervation of the rat diaphragm a) muscle fibers respond differently to the process of denervation, with some fibers showing focal lesions and disorganization of fibrillar elements and organelles earlier than others; b) type II fibers appear more susceptible to the processes of degeneration resulting from denervation upon light microscopy; c) 12 weeks after denervation all muscle fibers are found to be atrophic.

ACKNOWLEDGEMENTS. The authors thank CNPq for support, proc. 141.412/98-4 
TORREJAIS, M. M.; SOARES, J. C.; MATHEUS, S. M. M.; FRANCIA-FARJE, L. A. D.; MELLO, J. M. \& VICENTE, E. J. D. Alteraciones morfológicas resultantes de la denervación del diafragma en ratas. Int. J. Morphol., 30(3):1150-1157, 2012.

RESUMEN: Fueron estudiadas las alteraciones morfológicas de las fibras musculares del diafragma denervado de ratas. Se utilizaron 15 ratas albinas (Rattus norvegicus) machos, adultos, con peso promedio de $200 \mathrm{~g}$ y cerca de 60 días de edad. Se denervó el diafragma y después de 4, 8 y 12 semanas los animales fueron sacrificados. El antímero izquierdo del diafragma fue denervado por sección del nervio frénico y el antímero derecho fue utilizado como control. Cada antímero fue dividido en fragmentos, utilizados para el estudio histológico (H-E), histoenzimológico (NADH-TR y ATPasa miofibrilar). Después de 4 semanas las fibras musculares denervadas presentaron alteraciones importantes en lamicroscopía de luz: atrofia con perfiles angulados en secciones transversales; citoplasma con vacuolas; aumento del espacio intersticial con aumento de tejido conjuntivo; infiltración celular y fibras musculares sin contornos definidos, siendo las alteraciones más marcadas en las fibras tipo IIb e IIa. Después de 8 y 12 semanas de denervación la reacción para NADH-TR demuestra que es imposible caracterizar a las fibras musculares a través de su perfil metabólico.

PALABRAS CLAVE: Diafragma; Fibra muscular; Denervación; Rata.

\section{REFERENCES}

Anzil, A. P. \& Wernig, A. Muscle fibre loss and reinnervation after long-term denervation. J. Neurocytol., 18(6):833-45, 1989.

Banker, B. Q. \& Engel, A. G. Basic reactions of muscle. In: Engel, A. G. \& Frazini-Armstrong, C. (Eds.). Myology: basic and clinical. 2nd ed. New York, Edition International, 1994. pp.832-88.

Brazil, O. V. Neuromuscular action of Micrurus venom. Hospital (Rio J), 68(4):909-50, 1965.

Brooke, M. H. \& Kaiser, K. K. Three "myosin adenosine triphosphatase" systems: the nature of their pH lability and sulfhydryl dependence. J. Histochem. Cytochem., 18(9):670-2, 1970.

Cotran, R. S.; Kumar, V. \& Collins, T. Robbins pathologic basis of disease. 6rd ed. Philadelphia, W.B. Saunders, 1999. p.1425.

Cullen, M. J.; Fohnson, M. A. \& Mastaglia, F. L. Pathological reactions of skeletal muscle. In: Mastaglia, F. L. \& Walton, J. N. (Eds.). Skeletal muscle pathology. Edinburgh, Churchill Livingstone, 1992. pp.123-84.

Dubowitz, V. \& Brooke, M. Muscle biopsy: a mordern approach. London, Saunders, 1973. p.475.

Edström, L. \& Kugelberg, E. Histochemical composition, distribution of fibers and fatigability of single motor units. Anterior tibial muscle of the rat. J. Neurol. Neurosurg. Psychiatry, 31(5):42433, 1968.

Engel, A. G. Vacuolar myopathies: multiple etiologies and sequential structural studies. In: Pearson, C. M. \& Mostofi, F. K. (Eds.). The striated muscle. Baltimore, Williams \& Wilkins, 1973. pp.30141.

Engel, A. G.; Gomes, M. R. \& Groover, R. V. Multicore disease. A recently recognized congenital myopathy associated with multifocal degeneration of muscle fibers. Mayo Clin. Proc., 46(10):666-81, 1971.

Engel, A. G. \& Banker, B. Q. Ultrastructural changes in diseased muscle. In: Engel, A. G. \& Frazini-Armstrong, C. (Eds.). Myology: basic and clinical. $2^{\text {nd }}$ ed. New York, Edition International, 1994. pp.889-1017.

Engel, A. G. \& Stonnington, H. H. Morphological effects of denervation of muscle: A quantitative ultrastructural study. Ann. N. Y. Acad. Sci., 228:68-88, 1974.

Harriman, D. G. F. General pathological reactions of muscle fibres. In: Weller, R. O. (Ed.). Nerves system, muscle and eyes. Edinburgh, Churchill Livingstone, 1990. pp.588-603.

Karpati, G. \& Engel, W. K. Histochemical investigation of fiber type ratios with the myofibrilar ATPase reaction in normal and denervated skeletal muscles of guinea pig. Am. J. Anat., 122(1):145-56, 1968.

Khan, M. A. The histoenzymology of striated muscle fibers na overview. Cell. Mol. Biol. Incl. Cyto. Enzymol., 22(3-4):383-93, 1977.

McComas, A. J. Neuromuscular junction and disorders. London, Butterworth, 1977. p.364.

Moline, S. W. \& Glenner, G. G. Ultra rapid tissue freezing in liquid nitrogen. J. Histochem. Cytochem., 12:777-8, 1964.

Pearse, A. G. E. Histochemistry: theoretical and applied. 3rd ed. Baltimore, Williams \& Wilkins, 1972. pp.921-61.

Pullen, A. H. The distribution and relative size of fibre types in the extensor digitorum longus and soleus muscles of the adult rat. $J$. Anat., 123(Pt 2):467-86, 1977.

Scriver, C. R.; Beaudet, A. L.; Sly, W. S. \& Valle, D. The metabolic basis of inherited disease. $6^{\text {nd }}$ ed. New York, McGraw-Hill, 1989.

Correspondence to:

Profa. Dra . Marcia Miranda Torrejais

Medical and Pharmaceutic Sciences Center

University of the State of Paraná

UNIOESTE - 85814-110, Cascavel, Paraná

BRAZIL

Received: 26-11-2011

Accepted: 16-03-2012

Email: mmtorrejais@yahoo.com.br 